\title{
Incidence and risk factors for cognitive impairment in rural elderly populations in Costa Rica
}

\author{
Jeffrey L. Nadel \& Diana Ulate \\ Associated Colleges of the Midwest, San Pedro Montes de Oca, Costa Rica; jeffrey.nadel@gmail.com, \\ acmcostarica@acm.edu
}

Received 20-III-2014. Corrected 20-IV-2014. Accepted 15-V-2014.

\begin{abstract}
Risk factors for the onset of cognitive impairment in Costa Rica are not well understood, despite a substantial elderly population stemming from a higher than average life expectancy for the western hemisphere. To investigate the risk factors that predict the onset of cognitive impairment in the rural elderly of Costa Rica, a modified version of the Mini Mental State Exam — designed for illiterate populations - was administered to 90 elderly inhabitants of San Carlos, Alajuela, Costa Rica between April and May of 2011. Subsequently, each participant took a structured interview assessing viability of risk factors and behaviors potentially contributing to a diagnosis of cognitive impairment. Results showed strong dependencies between age $(p=0.0001)$, education level $(p=0.0095)$, the ability to read $(p=0.0001)$ and write $(p=0.0153)$, frequency of reading $(p=0.0011)$, use of puzzles and mind games $(\mathrm{p}<0.0001)$, vocation $(\mathrm{p}=0.0225)$, area of residence $(\mathrm{p}<0.0001)$, comorbid mental diseases $(p=0.0005)$, history of stroke or brain trauma $(p=0.0104)$, urinary or renal problems $(p=0.0443)$, consistent cooking practices $(p=0.0262)$ and number of living companions $(p=0.0299)$ in susceptibility for developing cognitive impairment. The study concluded that high intellectual use, or lack thereof, during the lifetime of a person was a predictor for cognitive status later in life. In addition, comorbid mental disorders, including neurological trauma due to stroke, impeded normal cognitive function. Future research should examine incidence and risk factors of cognitive impairment in urban, more educated populations. Rev. Biol. Trop. 62 (3): 869-876. Epub 2014 September 01.
\end{abstract}

Key words: cognitive impairment, dementia, education, elderly, mini mental state exam, Costa Rica.

Although widely applicable to the Costa Rican public health sector, risk factors for cognitive impairment in Costa Rica are not well understood. With a substantial elderly population stemming from a higher than average life expectancy for the western hemisphere, and a portion of this population living in rural areas of the country, incapacitation attributable to cognitive malfunction in the rural elderly is prevalent (Cáceres-Rodas, 2004). Cognitive impairment is a key indicator for a diagnosis of dementia, defined as a progressive, global or local loss of proper mental function (Yen et al., 2010). The primary symptoms associated with dementia are characterized in the Diagnostic and Statistical Manual of Mental Disorders, $4^{\text {th }}$ Edition, Text Revision (DSM-IV
TR), and include memory loss, attention deficits, a loss of problem solving skills, mood and attitude changes, and trouble producing and understanding language (American Psychiatric Association, 2000). Dementia is a characteristic symptom of several mental health disorders also diagnosable through DSM-IV TR criteria, including Alzheimer's disease (AD). In fact, people diagnosed with Mild Cognitive Impairment $(\mathrm{MCI})$ are at significant risk for developing $\mathrm{AD}$ and other age-related neurodegenerative disorders (Belleville, Sylvain-Roy, de Boysson, \& Ménard, 2008; Li et al., 2011; Petersen et al., 1999; Petersen et al., 2001).

With the current rate at which globally applicable biomedical research is advancing, the average human life span is dramatically 
increasing. Costa Rica is no exception. According to the 1984 census, there were 158144 people over the age of 60 in Costa Rica, comprising approximately $6.5 \%$ of the population. The 2000 census revealed an increase to 301 474 people over the age of 60 , making up $7.9 \%$ of the Costa Rican population. Current projections for the year 2015 place the estimated elderly population at 557 076, which would correlate to more than $11.1 \%$ of the population (Cáceres-Rodas, 2004; Centro Centroamericano de Población, 2011). Additionally, portions of Costa Rica have been designated a Blue Zone, which are defined as special areas of the world with high numbers of living centenarians (Buettner, 2010). With this rapidly aging population, it is becoming increasingly important to assess the prevalence of cognitive impairment, identify risk factors associated with such impairment, and educate the public on ways to preserve their mental status as they age.

Numerous studies in other countries have shown that age, gender, education level, cardiovascular health, daily nutritional value, living situation, pollution, consumption of tobacco and alcohol, and other comorbid mental and non-mental diseases are significant risk factors for a diagnosis of cognitive impairment (Yen et al., 2010; Heun \& Hein, 2005; Lee, Hong, Cheong, \& Oh, 2009; Sánchez-Rodríguez, Santiago, Arronte-Rosales, Vargas-Guadarrama, Mendoza-Núñez, 2006; van Exel et al., 2002). However, a unique climate, economy, culture, location, and greater than average life expectancy contribute to risk factors specific to Costa Rica. Cáceres-Rodas (2004) explored the relationship between physical health and mental health in the outer lying rural and quasi-urban parts of the Central Valley of Costa Rica. This study, though, did not specifically investigate behavioral, social, or cultural risk factors for cognitive impairment.

The objectives of this study were to: a) individually assess elderly patients in Florencia and Ciudad Quesada for differences in the incidence rate of cognitive impairment using the Mini Mental State Exam; b) assess potential risk factors for cognitive impairment in a structured interview following the Mini Mental State Exam; and c) estimate the correlations between risk factors and presence and severity of cognitive impairment.

\section{MATERIALS AND METHODS}

Study site: This study was carried out in two locations: Florencia, San Carlos, Alajuela, Costa Rica $\left(10^{\circ} 22^{\prime} 0^{\prime \prime} \mathrm{N}\right.$ and $\left.84^{\circ} 29^{\prime} 0^{\prime \prime} \mathrm{W}\right)$ and Ciudad Quesada, San Carlos, Alajuela, Costa Rica $\left(10^{\circ} 20^{\prime} 0^{\prime \prime} \mathrm{N}\right.$ and $84^{\circ} 26^{\prime} 0^{\prime \prime} \mathrm{W}$ ) (Centro Centroamericano de Población, 2011).

Study population: The study population was anyone over the age of 60 as defined as elderly for rural research by the World Health Organization (2011). All participants fulfilled one or more of the following three criteria to create a random sample: a) being part of a nonresidential, elderly support group in the above districts; b) living in an elderly institution providing around-the-clock medical and social assistance; c) in their home when interviewed by the researcher in neighborhoods of Ciudad Quesada and Florencia, San Carlos, Alajuela, Costa Rica.

Interview criteria: Human participants and treatment during the interview was in accordance with the International Ethical Guidelines for Biomedical Research Involving Human Subjects as set forth by the Council for International Organizations of Medical Sciences in collaboration with the World Health Organization in 2002. Prior to the interview, all participants signed a standard consent form explaining information about the purpose of the study, the rights of the participant, and the risks of involvement. The form was read to each participant orally to ensure that all participants fully understood the implications of their participation. Literate subjects signed their name and illiterate participants supplied their fingerprint to confirm their consent.

Subsequently, a modified version of the Mini Mental State Exam (MMSE) was administered to determine whether or not there was 
an incidence of cognitive impairment and if so, to what degree. This rural population had a high percentage of illiterate and uneducated elderly persons. As such, an adjusted version of the MMSE designed for uneducated and illiterate populations was utilized (Kabir \& Herlitz, 2000).

After administration of the MMSE, all patients underwent a structured interview survey aimed at assessing risk factors for cognitive impairment. Both of these examinations were administered orally in an interview format.

Assessment survey variables: Variables examined in the risk-factor assessment survey included: a) mental exercises - participant regularly completes puzzles, word searches, crossword puzzles, plays cards, dominoes, or other mental puzzles or exercises; b) location of residence-participant lived only in a rural region, in both a rural and urban region, or only in an urban region during their life; c) ability to read-a self report of whether the participant can read well, can barely read, or cannot read at all; d) age - participant is 60-70yrs old, 71-80yrs old, or 81+yrs old; e) comorbid mental issues - self report of whether the patient has been diagnosed with mental or neurological conditions such as depressed continuously for more than one month, issues with anxiety or nervousness, or takes or has taken treatments for mental problems; f) frequency of readingparticipant reads everyday, reads $2-6 \mathrm{~d}$ of the week, or reads less than one time per week; g) formal education-participant received no formal education, completed 1-2 grade, completed 3-4 grade, completed 5-6 grade, or received more than six years of formal education; $h$ ) stroke - participant has had a stroke, or another form of vascular or cerebral trauma; i) ability to write - participant can write more than their name, or the participant can write only their name, or the participant cannot write; j) vocation-participant was an agricultural worker, was a home-maker, or worked in business, commerce, or city-oriented jobs; k) cooked for themselves - participant was responsible for preparing their own meals, or does not prepare their own meals; 1) living companions - participant lives alone, lives with 1-3 others, or lives with four or more other people; m) urinary problems-participant suffers from urinary problems, or does not suffer from urinary problems; n) tv watching time - participant watches less than one hour of television per day, 1-3hrs of television per day, or more than 3 hours of television per day; o) diabetes-participant suffers from either Type I or Type II Diabetes, or does not suffer from diabetes; $p$ ) living siblings - participant has three or fewer siblings still living, or has four or more living siblings; q) cholesterol-participant is currently suffering from high cholesterol, has suffered from high cholesterol in the past, or does not and has never suffered from high cholesterol; r) number of children - participant's has reared three or fewer children, or has reared four or more children; s) number of surgeries - participant has had 2 or more surgeries, or has had 1 or fewer surgeries; t) death of a child - participant has reared a child who has subsequently died, or all of the children of the participant are still living; u) colon problems - participant suffers from any number of intestinal problems including, but not limited to, colitis, or the participant does not suffer from colon problems; v) smoker or past smoker-participant currently smokes or has smoked in the past, or the participant has never smoked; w) family mental issuessomeone in the participants family has suffered from mental disease, stroke, or brain trauma, or no one in the family has suffered from mental or neurologic problems; $x$ ) gender-participant is male or female; y) eats dinner-participant eats dinner regularly, or participant does not eat dinner; z) pregnancy frequency - female only: participant has been pregnant four or fewer times, or five or more times; aa) drinker or past drinker-participant currently or habitually consumed alcoholic beverages now or in the past, or has never consumed alcoholic beverages; ab) tv companions_-participant watches TV alone, or watches with other people; ac) heart attack - participant has had a heart attack, or the participant has never had a heart attack; ad) hypertension-participant is currently 
suffering from hypertension, or has suffered from hypertension in the past; ae) cardiovascular-participant self reports that a doctor has previously told them that they have heart problems, or that they have never been informed of heart problems; and af) gastric problemsparticipant suffers from any number of gastric problems including, but not limited to, gastritis, or does not suffer from gastric problems.

The MMSEs were scored, and overall prevalence of cognitive impairment was estimated. Participants were considered cognitively impaired by scoring below 25 out of 30 possible points on the MMSE. A score of $\leq 9$ points indicated severe cognitive impairment, a score of 10-20 points indicated moderate cognitive impairment, and a score of 20-24 indicated mild cognitive impairment.

This measured independence between individual risk factors and incidence of cognitive impairment through contingency tables. Each severity category was not analyzed with each variable. Only the overall incidence (all severity categories combined) or lack of cognitive impairment was measured against the individual risk factor variables. Statistical tests followed Sokal \& Rohlf (1995) and were run with Statgraphics Centurion XVI.I software (Statpoint Technologies, Inc., 2011).

\section{RESULTS}

This study included a total of 90 participants. One participant underwent administration of a non-modified MMSE for illiterate populations, was unable to be re-tested with an unbiased form of the exam, and was thus excluded from analysis. Of those included, $60.6 \%$ were women. Mean age of participants was $76.8 \pm 8.1$ (Mean \pm S.D.) years; $33.7 \%$ were over the age of 80 . In terms of educational status, $5.6 \%$ received more than a primary education, with $41.6 \%$ of participants having completed the second year of formal primary education or less. The majority of the study population (96.6\%) was born in Costa Rica. Overall incidence of cognitive impairment (mild, moderate and severe combined) was
$48.3 \%$. Of those impaired, $48.8 \%$ were mildly impaired, $48.8 \%$ were moderately impaired, and $2.3 \%$ were severely impaired.

Results of bi-variate contingency table analysis of independence between individual risk factor variables and the incidence of cognitive impairment are summarized in table 1. Specific elucidation of three statistically significant risk factor variables - formal education, vocation, and age - can be seen in a categorical breakdown in Figs. 1-3, respectively.

There was a significant dependency of the selection group sampled on the incidence of cognitive impairment $\left(\mathrm{X}^{2}=8.9, \mathrm{df}=3, \mathrm{p}=0.030\right)$.

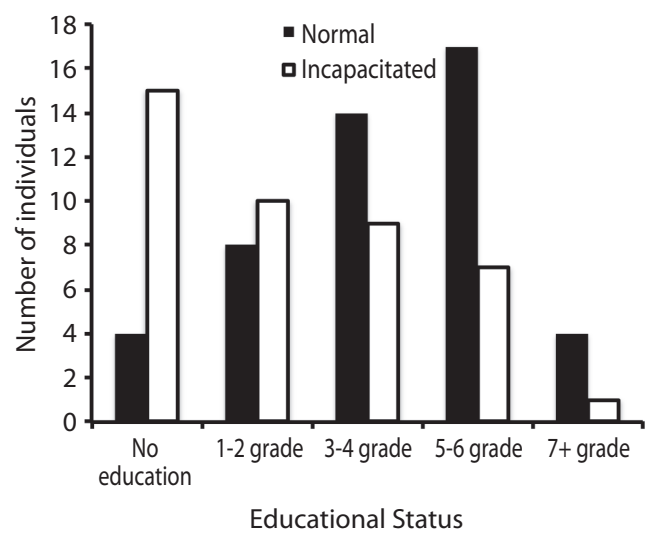

Fig. 1. Frequency of participants and their obtained educational level as it corresponds to mental state, AprilMay 2011, San Carlos, Costa Rica.

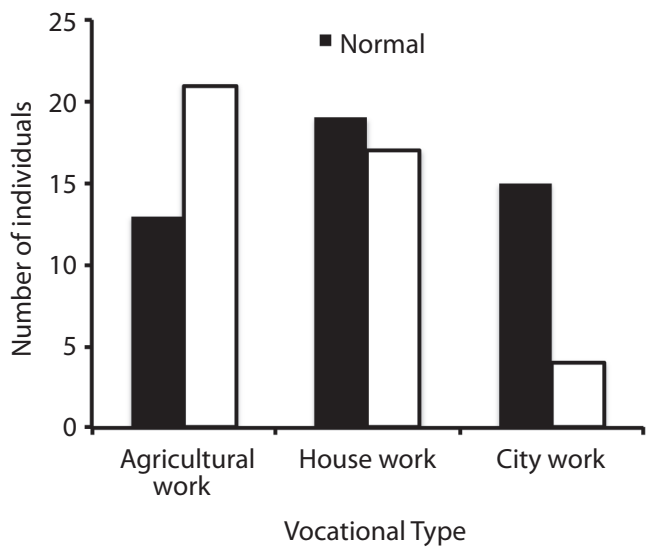

Fig. 2. Frequency of participants and their vocational type as it corresponds to mental state, April-May 2011, San Carlos, Costa Rica. 
TABLE 1

Contingency table analysis of independence between individual risk factor variables and the incidence of cognitive impairment. San Carlos, Costa Rica. April-May 2011

\begin{tabular}{|c|c|c|c|}
\hline Risk Factor Variables & $\mathrm{X}^{2}$ (Chi-Squared) & Degrees of Freedom & $\mathrm{p}$ \\
\hline Mental Exercises & 18.417 & 1 & $<0.0001 *$ \\
\hline Location of Residence & 20.509 & 2 & $<0.0001 *$ \\
\hline Ability to Read & 17.896 & 2 & $0.0001 *$ \\
\hline Age & 19.297 & 2 & $0.0001 *$ \\
\hline Comorbid Mental Issues & 12.105 & 1 & $0.0005^{*}$ \\
\hline Frequency of Reading & 13.555 & 2 & $0.0011^{*}$ \\
\hline Formal Education & 13.406 & 4 & $0.0095 *$ \\
\hline Stroke & 6.565 & 1 & $0.0104 *$ \\
\hline Ability to Write & 5.822 & 1 & $0.0153 *$ \\
\hline Vocation & 7.591 & 2 & $0.0225^{*}$ \\
\hline Cooked for Themselves & 4.945 & 1 & $0.0262 *$ \\
\hline Living Companions & 4.715 & 1 & $0.0299 *$ \\
\hline Urinary Problems & 4.044 & 1 & $0.0443 *$ \\
\hline TV Watching Time & 2.740 & 1 & 0.0979 \\
\hline Diabetes & 1.927 & 1 & 0.1651 \\
\hline Living Siblings & 1.857 & 1 & 0.1730 \\
\hline Cholesterol & 1.829 & 1 & 0.1762 \\
\hline Number of Children & 1.084 & 1 & 0.2979 \\
\hline Number of Surgeries & 0.934 & 1 & 0.3337 \\
\hline Death of Child & 0.757 & 1 & 0.3842 \\
\hline Colon Problems & 0.685 & 1 & 0.4078 \\
\hline Smoker or Past Smoker & 0.440 & 1 & 0.5072 \\
\hline Family Mental Issues & 0.440 & 1 & 0.5072 \\
\hline Gender & 0.435 & 1 & 0.5097 \\
\hline Eats Dinner & 0.116 & 1 & 0.7332 \\
\hline Pregnancy Frequency & 0.092 & 1 & 0.7613 \\
\hline Drinker or Past Drinker & 0.054 & 1 & 0.8163 \\
\hline TV Companions & 0.036 & 1 & 0.8499 \\
\hline Heart Attack & 0.028 & 1 & 0.8675 \\
\hline Hypertension & 0.020 & 1 & 0.8867 \\
\hline Cardiovascular & 0.015 & 1 & 0.9012 \\
\hline Gastric Problems & 0.014 & 1 & 0.9050 \\
\hline
\end{tabular}

*Denotes statistical significance at the $\mathrm{p} \leq 0.05$ level.

Residents of the Hogar de Ancianos had the most impairment (77.8\%), followed by Ciudad Quesada (42.3\%), and then Florencia (41.7\%). The lowest proportion of impairment was noted in the group collected house to house (33.4\%).

\section{DISCUSSION}

Nearly all of the significant risk factors leading to increased impairment shared the common theme of lack of mental stimulation.
Higher levels of brain input and stimulation appeared to exhibit neuroprotective effects as the study population aged. Acquiring and/ or sustaining formal education by frequently reading, writing, and completing puzzles also appeared to aid in staving off brain atrophy. Additionally, both a city-oriented vocation that requires enhanced daily thought processing and a home in a suburban or city atmosphere where more visual, auditory, and interpersonal stimulation exists had seemingly similar effects. 


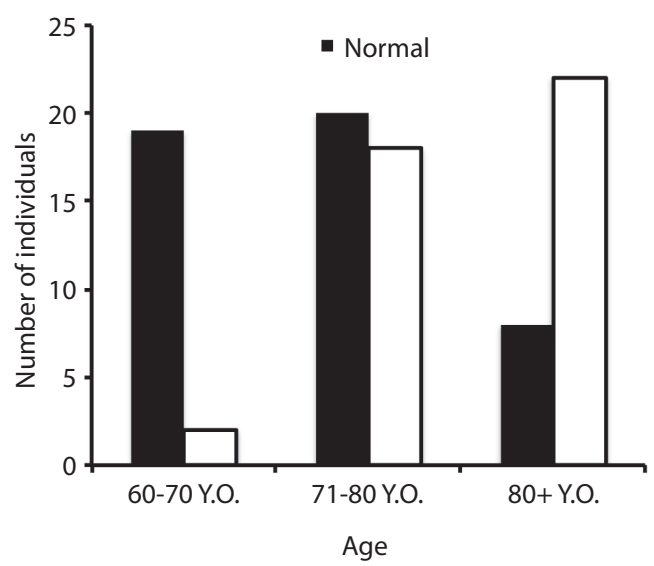

Fig. 3. Frequency of individuals and their age as it corresponds to mental state, April-May, 2011, San Carlos, Costa Rica.

Numerous studies have found strong trends suggesting education level as a predictor for the onset of cognitive impairment, and that participation in life-long intellectual activity can be an important factor in staving off such symptoms (Callahan et al., 1996; Kliegel, Zimprich, \& Rott, 2004; Marcopulos, McLain, \& Giuliano, 1997; White et al., 1994). Similarly, intellectual stimulation can be seen as a technique to attenuate the harsh effects of cognitive impairment when it acts as a characteristic symptom of neurologic disorders such as multiple sclerosis (Sumowski, Wylie, Chiaravalloti, \& DeLuca, 2010). As such, it is becoming clearer that higher intake of life-long intellectual stimuli is essential for resiliency in cognitive status, regardless of age or comorbid disease.

Regarding implications of brain traumas in impairment, not surprisingly, patients who had previously sustained brain trauma, whether in the form of stroke, or other, were significantly more impaired than their non-affected counterparts. A stroke is any interruption of blood supply to the brain, either by blockage or bursting (PubMed Health, 2011). The implications of a stroke, according to the same source, can cause lasting brain damage and mal-effects in speech production and comprehension, movement, bladder and bowl problems, issues with cognition and memory, among others. Furthermore, only about half of stroke patients regain enough function to independently care for themselves (PubMed Health, 2011). Thus, it is logical that stroke survivors tested significantly for increased cognitive impairment.

Regarding implications of dangerous behaviors in impairment, behaviors such as chronic smoking and drinking showed no significant effect on cognitive impairment in this study, debate still exists about the roles that smoking and alcohol consumption play in general cognition and incapacity (Hill, 1989; Reitz, Luchsinger, Tang, \& Mayeux, 2005; Kalmijn, van Boxtel, Verschuren, Jolles, \& Launer, 2002).

Gender played an insignificant role as an indicator for cognitive impairment in this study. Interestingly, Yen et al. (2010) reported females at higher risk for cognitive impairment. However, van Exel et al. (2001) showed women less prone to the development of cognitive impairment. Obvious debate exists, prompting the necessity for unbiased sampling. The present study is prone to a similar type of sample bias given the gender demographics of the sample population. In this sample population, greater than $60 \%$ of participants were female. The majority of male participants were interviewed in the Hogar de Ancianos, a hospital-type institution where more than $70 \%$ of residents interviewed exhibited cognitive impairment. Thus, with a higher than representative sample of impaired males, and a larger than $60 \%$ sample of females, it is possible that the sample bias contributed to a non-significant role of gender in cognitive impairment.

Additionally, the majority of health-oriented comorbidities in this study did not appear as significant indicators for a diagnosis of cognitive impairment. Significant correlations were previously reported for diabetes and cardiovascular disease as predictors of cognitive impairment (Yen et al., 2010; van Exel et al., 2002). However, the study population assessed in Yen et al. (2010) was nearly 10 yrs younger on average than in the present study. Further, van Exel et al. (2002) implemented the use of 
electrocardiogram technology, and in-depth analysis of patient charts. Each of these methodological disparities can contribute to differences in findings.

Finally, self-reported data often provides a skewed view of the medical history of the patient. Patients may not understand exactly what a doctor is saying during consultations, especially in a highly uneducated, rural population. Thus, readers must take into account the means by which the data was collected when generalizing about the apparent insignificance of existing health comorbidities.

\section{ACKNOWLEDGMENTS}

We thank Chris Vaughan and Michael McCoy for their tireless efforts to make this project a success, help on statistical analysis, and manuscript edits. We also thank Olga Mora, Albino Riveras, and Dayma Morales, directors and overseers of the elderly institutions in San Carlos de Alajuela, Costa Rica. And finally, thanks are given to all study participants who selflessly shared their stories, insights, fears, and lives during this experience.

\section{RESUMEN}

Incidencia y factores de riesgo para la discapacidad cognitiva en poblaciones rurales de tercera edad en Costa Rica. Los factores de riesgo asociados con el inicio de la discapacidad cognitiva en Costa Rica son poco comprendidos, a pesar de la existencia de una considerable población de la tercera edad que ha resultado de una expectativa de vida mayor que el promedio en el hemisferio occidental. Para investigar los factores de riesgo que indican el inicio de la discapacidad cognitiva en adultos mayores de zonas rurales en Costa Rica, se les administró una versión modificada del Mini Examen del Estado Mental diseñado para poblaciones analfabetas a 90 adultos mayores residentes en San Carlos de Alajuela, Costa Rica, entre abril y mayo 2011. Posteriormente cada participante recibió una entrevista estructurada para evaluar la viabilidad de los factores de riesgo y comportamientos que podrían contribuir a un diagnóstico de discapacidad cognitiva. Los resultados mostraron una fuerte relación de dependencia entre la edad $(p=0.0001)$, el nivel educativo $(p=0.0095)$, la capacidad de leer $(\mathrm{p}=0.0001)$ y escribir $(\mathrm{p}=0.0153)$, la frecuencia de lectura $(\mathrm{p}=0.0011)$, la utilización de rompecabezas $\mathrm{y}$ juegos de estímulo intelectual $(\mathrm{p}<0.0001)$, la vocación $(p=0.0225)$, el lugar de residencia $(p<0.0001)$, las enfermedades mentales comórbidas $(\mathrm{p}=0.0005)$, un historial de derrame o de trauma cerebral $(\mathrm{p}=0.0104)$, los trastornos urinarios o renales $(\mathrm{p}=0.0443)$, la preparación de alimentos en forma consistente $(\mathrm{p}=0.0262)$, el número de personas con quienes convive $(\mathrm{p}=0.0299)$ y la susceptibilidad de desarrollar la discapacidad cognitiva. El estudio concluyó que un alto nivel de uso del intelecto, o la falta del mismo, durante la vida es un indicador del estatus cognitivo en etapas más avanzadas de la vida. Además, se encontró que las enfermedades mentales comórbidas, como el trauma neurológico provocado por un derrame cerebral, impiden la función cognitiva normal. Se recomienda que futuras investigaciones examinen la incidencia y los factores de riesgo asociados con la discapacidad cognitiva en poblaciones urbanas de mayores niveles educativos.

Palabras clave: discapacidad cognitiva, demencia, educación, adulto mayor, mini examen del estado mental, Costa Rica.

\section{REFERENCES}

American Psychiatric Association. (2000). Diagnostic and Statistical Manual of Mental Disorders. (DSM-IVTR). Arlington, VA, USA: American Psychiatric Association.

Belleville, S., Sylvain-Roy, S., de Boysson, C., \& Ménard, M. C. (2008). Characterizing the memory changes in persons with mild cognitive impairment. Progress in Brain Research, 169, 365-375.

Buettner, D. (2010). The blue zones: Lessons for living longer from the people who've lived the longest. Washington, D. C., USA: National Geographic Books.

Cáceres-Rodas, R. I. (2004). Estado de salud físico y mental de los adultos mayores del área rural de Costa Rica. Población y salud en Mesoamérica, 1(2). Retrived from http://revistas.ucr.ac.cr/index.php/psm/ article/view/13931

Callahan, C. M., Hall, K. S., Hui, S. L., Musick, B. S., Unverzagt, F. W., \& Hendrie, H. C. (1996). Relationship of age, education, and occupation with dementia among a community-based sample of African americans. Archives of Neurology, 53(2), 134-140.

Centro Centroamericano de Población. (2011). Estimaciones y Proyecciones de Población por sexo y edad 1950-2100 (cifras actualizadas). Universidad de Costa Rica. Retrieved from http://censos.ccp.ucr. ac.cr /cgi-bin/login.pl

Heun, R. \& Hein, S. (2005). Risk factors of major depression in the elderly. European Psychiatry, 20(3), 199-204.

Hill, R. D. (1989). Residual effects of cigarette smoking on cognitive performance in normal aging. Psychology and Aging, 4(2), 251-254. 
Kabir, Z. N. \& Herlitz, A. (2000). The Bangla Adaptation of Mini-mental State Examination (BAMSE): An instrument to assess cognitive function in illiterate and literate individuals. International Journal of Geriatric Psychiatry, 15(5), 441-450.

Kalmijn, S., van Boxtel, M. P. J., Verschuren, M. W. M., Jolles, J., \& Launer, L. J. (2002). Cigarette smoking and alcohol consumption in relation to cognitive performance in middle age. American Journal of Epidemiology, 156(10), 936-944.

Kliegel, M., Zimprich, D., \& Rott, C. (2004). Life-long intellectual activities mediate the predictive effect of early education on cognitive impairment in centenarians: A retrospective study. Aging and Mental Health, 8(5), 430-437.

Lee, K. S., Hong, C. H., Cheong, H. K., \& Oh, B. H. (2009). Difference in nutritional risk between mild cognitive impairment group and normal cognitive function elderly group. Archives of Gerontology and Geriatrics, 49(1), 49-53.

Li, H., Li, J., Li, N., Li, B., Wang, P., \& Zhou, T. (2011). Cognitive intervention for persons with mild cognitive impairment: A meta-analysis. Ageing Research Reviews, 10(2), 285-296.

Marcopulos, B., McLain, C. A., \& Giuliano, A. J. (1997). Cognitive impairment or inadequate norms? A study of healthy, rural, older adults with limited education. The Clinical Neuropsychologist, 11(2), 111-131.

Petersen, R. C., Doody, R., Kurz, A., Mohs, R. C., Morris, J. C., Rabins, P. V., Ritchie, K., Rossor, M., Thal, L., \& Winblad, B. (2001). Current concepts in mild cognitive impairment. Archives of Neurology, 58(12), 1985-1992.

Petersen, R. C., Smith, G. E., Waring, S. C., Ivnik, R. J., Tangalos, E. G., \& Kokmen, E. (1999). Mild cognitive impairment: Clinical characterization and outcome. Archives of Neurology, 56(3), 303-308.

PubMed Health. (2011). Stroke. Retrieved from http:// www.ncbi.nlm.nih.gov/pubmedhealth/PMH0001740/

Reitz, C., Luchsinger, J., Tang, M. X., \& Mayeux, R. (2005). Effect of smoking and time on cognitive function in the elderly without dementia. Neurology, 65(6), 870-875.
Sánchez-Rodríguez, M. A., Santiago, E., Arronte-Rosales, A., Vargas-Guadarrama, L. A., \& Mendoza-Núñez, V. M. (2006). Relationship between oxidative stress and cognitive impairment in the elderly of rural vs. urban communities. Life Sciences, 78(15), 1682-1687.

Sokal, R. R. \& Rohlf, F. J. (1995). Biometry: The principles and practice of statistics in biological research. New York, USA: W. H. Freeman and Co.

Statpoint Technologies, Inc. (2011). Statgraphics Centurion [computer software]. Available from http://www. statgraphics.com.

Sumowski, J. F., Wylie, G. R., Chiaravalloti, N., \& DeLuca, J. (2010). Intellectual enrichment lessens the effect of brain atrophy on learning and memory in multiple sclerosis. Neurology, 74(24), 1942-1945.

van Exel, E., Gussekloo, J., de Craen, A. J. M., Bootsmavan der Wiel, A., Houx, P., Knook, D. L., \& Westendorp, R. G. J. (2001). Cognitive function in the oldest old: Women perform better than men. Journal of Neurology, Neurosurgery \& Psychiatry, 71(1), 29-32.

van Exel, E., Gussekloo, J., Houx, P., de Craen, A. J. M., Macfarlane, P. W., Bootsma-van der Wiel, A., Blauw, G. J., \& Westendorp, R. G. (2002). Atherosclerosis and cognitive impairment are linked in the elderly. The Leiden 85-plus study. Atherosclerosis, 165(2), 353-359.

White, L., Katzman, R., Losonczy, K., Salive, M., Wallace, R., Berkman, L., Taylor, J., Fillenbaum, G., \& Havlik, R. (1994). Association of education with incidence of cognitive impairment in three established populations for epidemiologic studies of the elderly. Journal of Clinical Epidemiology, 47(4), 363-374.

World Health Organization. (2011). Definition of an older or elderly person. Retrieved from http:/www.who. int/healthinfo/survey/ageingdefnolder/en/index.htm

Yen, C. H., Yeh, C. J., Wang, C. C., Liao, W. C., Chen, S. C., Chen, C. C, Liang, J., Lai, T. J., Lin, S. H., \& Lee, M. C. (2010). Determinants of cognitive impairment over time among the elderly in Taiwan: Results of the national longitudinal study. Archives of Gerontology and Geriatrics, 50(suppl 1), S53-S57. 